BIOKEMISTRI 19(2):49-52 (December 2007)

This article is downloadable online in PDF format at http://www.bioline.org.br/bk

Printed in Nigeria
An international journal published by the<smiles>c1ccccc1</smiles>

Oigerian Society for E̊xperimental Siology

\title{
Effects of Roasted Yam (Discorea rotundata Poir.) on Erythrocyte Osmotic Fragility and Other Haematologic Values in Male Albino Rats
}

\author{
Luqman Aribidesi OLAYAKI ${ }^{1 *}$, Ayo Olufemi SOLADOYE ${ }^{1}$, Olusegun Rabiu JIMOH ${ }^{2}$ \\ and Ayokunle OLAWEPO ${ }^{2}$
}

Departments of ${ }^{1}$ Physiology and ${ }^{2}$ Anatomy, Faculty of Basic Medical Sciences, College of Health Sciences, University of Ilorin, PMB 1515, Ilorin, Nigeria

Received 19 October 2007

MS/No BKM/2007/048, (C) 2007 Nigerian Society for Experimental Biology. All rights reserved.

\begin{abstract}
The effects of roasted yam (Discorea rotundata Poir.) were studied on some hematologic parameters in male albino rats. Twenty four (24) adult male rats were divided into three groups of eight rats per group. Group I served as the control group, in which the rats were given normal rat chow. Group II rats served as the sham control and received normal rat chow mixed with $25 \%$ of finely ground yam, while group III served as experimental group and received normal rat chow mixed with $25 \%$ of finely ground roasted yam. At the end of the experimental period (6 weeks), animals in all the groups were sacrificed and blood samples were taken for the determination of red blood cell (RBC) count, hemoglobin $(\mathrm{Hb})$ concentration, and packed cell volume (PCV) and erythrocyte osmotic fragility. It was observed that roasted yam ingestion reduced $\mathrm{RBC}$ count, $\mathrm{PCV}$, and $\mathrm{Hb}$ concentration while it increased erythrocyte osmotic fragility rats $(\mathrm{p}<0.05)$. Ingestion of non-roasted yam did not have effect on the measured hematologic parameters. It is therefore concluded that ingestion of roasted yam might have a deleterious effect on some hematologic parameters.
\end{abstract}

Keywords: Hematologic parameters, Erythrocyte Osmotic Fragility, Roasted Yam

* Corresponding author. Email: luqmanolayaki@yahoo.com, Tel.:234-8033814880 


\section{INTRODUCTION}

Smoke condensates derived from grilling fish and meat have been known to exhibit potent mutagenic activity in rodents ${ }^{1,2}$. These mutagens/carcinogens are heterocyclic amines (HCAs), which humans are continuously exposed to in ordinary lifestyle. HCAs in foods are mainly produced from creatinin, creatinine, sugar and from amino acids in meat (upon heating). They are imidazoquinline, imidazoquinoxaline derivatives, and phenylimidazopyridine. HCAs are pluripotent in producing cancers in various organs including breast, colon ${ }^{3}$ and prostate ${ }^{4}$ which are increasing around the world.

Yam is a carbohydrate food that is commonly consumed in Nigeria. It is consumed in various forms such as boiled, pasted, fried, and roasted. The commonest mode of roasting yam in our environment is by open flame roasting. Yam is rich in protein, phosphorus, and potassium when compared to sweet potatoes ${ }^{5}$. White yam (Discorea rotundata Poir.) is the most common of the various types of yams that are consumed in this country. A thorough search of the literature reveals that there is no information on the effects of roasted yam on erythrocyte osmotic fragility even though it is consumed by many. The present study was therefore designed to investigate the effects of roasted yam on haematological parameters using rat as a model.

Because of the pluripotent nature of HCAs in causing cell damage and destruction, we investigated the effects of roasted yam on some hematological parameters.

\section{MATERIALS AND METHODS}

\section{Treatment of Rats}

Twenty four albino rats (Rattus norvegicus Muridae, $)^{6}$ weighing between 150 and $190 \mathrm{~g}$, were obtained from the Animal Breeding Unit of the Department of Biochemistry, University of Ilorin, were used for the study.
The rats were divided into three experimental groups (Control, Non-roasted yam-treated, and Roasted yam-treated) each containing eight rats. The control group received only normal rat chow as food, the non-roasted yam-treated was given rat chow that had been mixed with $25 \%$ of powdered yam, while the roasted yam-treated group was given normal rat chow mixed with $25 \%$ roasted yam powder. All animals were housed in plastic cages with stainless steel mesh cover under standard laboratory conditions (light period 6:30 a.m. to 7:00 p.m.; $25 \pm 2^{0} \mathrm{C}$; relative humidity 55\%) with water freely available. All the animals received humane care.

\section{Determination of Erythrocyte Osmotic Fragility}

The procedure was similar to that described earlier ${ }^{7}$. Eight centrifuge tubes (numbered 1-8) each containing $5 \mathrm{mls}$ of graded saline concentration $(0.1 \%-0.8 \%)$ were used. A ninth tube contained distilled water. $0.02 \mathrm{ml}$ of blood was collected from each rat (via a cut from tail pre-soaked in xylocaine) into each centrifuge tube. The contents were thoroughly mixed and incubated for 30 minutes at $29-30^{\circ} \mathrm{C}$. The tubes were then centrifuged at $10,000 \mathrm{~g}$ for 5 minutes. The supernatants were carefully decanted and the optical density (used as a measure of the degree of haemolysis) determined with a spectronic 20 spectrophotometer at 540U. The percentage haemolysis was plotted against the sodium chloride concentration for each animal and the saline.

\section{Determination of Other Blood Parameters}

All haematological parameters were determine by an automated haematological analyser, SYSMEX KY-21(SYSMEX Corporation, Japan), using whole blood sample.

\section{Statistical Analysis}

The data were expressed as mean \pm standard deviation (SD) and analyzed using analysis of variance (ANOVA). Student's $t$-test was used to test for differences among means for which ANOVA indicated a significant $(\mathrm{p} \leq 0.05) \mathrm{F}$ ratio. 


\section{RESULTS}

Table 1. shows the comparative haematological values of control and treated groups. RBC count, $\mathrm{PCV}$, and $\mathrm{Hb}$ concentration reduced significantly (RBC count $14 \%, \mathrm{p}<0.05, \mathrm{n}=8$; PCV 27\%, p <0.05, n=8; Hb 21\%, p<0.05, $\mathrm{n}=8$ ) in the roasted yam-treated group compared to the control group.

Table 1. Comparative Haematological values of control and treatment groups.

\begin{tabular}{|c|c|c|c|}
\hline & Control & $\begin{array}{c}\text { Non- } \\
\text { Roasted }\end{array}$ & Roasted \\
\hline $\begin{array}{c}\text { RBC Count } \\
\left(\times 10^{6} / \mu \mathrm{l}\right)\end{array}$ & $7.41 \pm 0.3^{\mathrm{a}}$ & $7.39 \pm 0.4^{\mathrm{a}}$ & $6.34 \pm 0.4^{\mathrm{b}}$ \\
\hline $\mathrm{PCV}(\%)$ & $45.8 \pm 2.9^{\mathrm{a}}$ & $46.8 \pm 1.3^{\mathrm{a}}$ & $33.4 \pm 2.6^{\mathrm{b}}$ \\
\hline $\begin{array}{c}\mathrm{Hb} \text { Conc } \\
(\mathrm{g} / \mathrm{dl})\end{array}$ & $14.6 \pm 1.2^{\mathrm{a}}$ & $15.1 \pm 1.9^{\mathrm{a}}$ & $11.6 \pm 0.5^{\mathrm{b}}$ \\
\hline
\end{tabular}

Values are expressed as mean $\pm S D$. Number of rats in each group $=5$.

${ }^{a b}$ Different superscripts on means $\pm S D$ along the same row indicate $p<0.05$

There was no statistical significant difference in $\mathrm{RBC}$ count, $\mathrm{PCV}$, and $\mathrm{Hb}$ concentration between the control group and non-roasted yam-treated group.

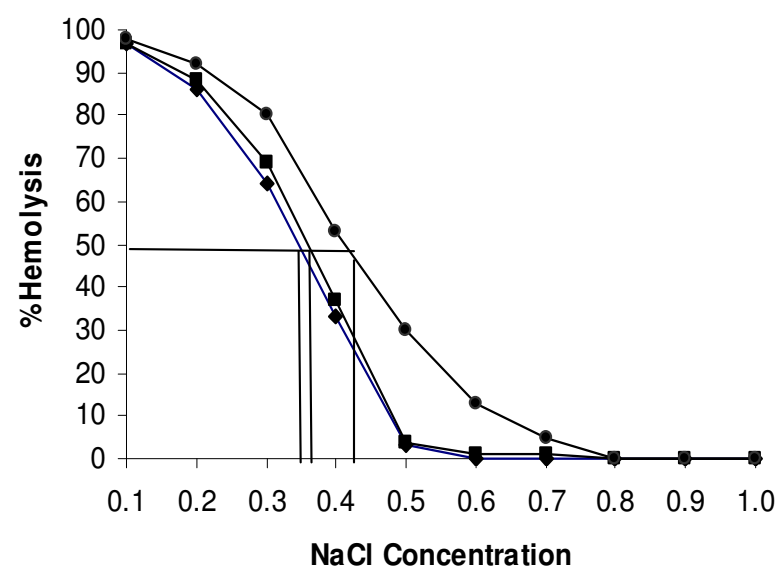

Fig. 1 Effect of roasted yam on osmotic fragility of erythrocytes. , Control, $\bullet$ Roasted Yam, Non-Roasted Yam

Fig. 1 shows the effect of roasted yam on osmotic fragility of erythrocytes. The osmotic fragility of erythrocytes from rats fed the roasted yam was significantly greater than those from group fed with normal rat chow and those fed with $25 \%$ non-roasted yam. Feeding animals with roasted yam significantly shifted the fragiligram to the right due to greater hemolysis. The median mean corpuscular fragility $\left(\mathrm{MCF}_{50}\right)$ in the animal fed with normal diet was $0.34 \pm 0.02 \%$. This value is significantly lower than the observed in the animal fed with roasted yam $(0.43 \pm 0.03 \%, \mathrm{p}<0.05, \mathrm{n}=8)$, but there was no statistical significant difference between the $\mathrm{MCF}_{50}$ of the rats fed with normal diet and those fed with ordinary powdered yam $(0.34 \pm 0.02 \%$ vs $0.36 \pm 0.01, \mathrm{p}>0.05, \mathrm{n}=8$ ). Hemolysis of $\mathrm{RBC}$ of roasted yam-treated rats start at about 0.75 $\mathrm{NaCl}$ concentration while that for normal fed rats and rats fed with powdered yam start at about $0.55 \mathrm{NaCl}$ concentration.

\section{DISCUSSION}

The present study observed a significant decrease in RBC count, $\mathrm{PCV}$, and $\mathrm{Hb}$ concentration following ingestion of $25 \%$ roasted yam in rat chow. There was also a significant increase in the reticulocytes count after ingestion of roasted yam. Previous studies have shown that charred and black crust materials on the surfaces of proteinacious foods, which are produced by contact with a naked flame, contain high level of $\mathrm{HCAs}^{8}$. Cooking of food is a process unique to humans. It enhances the taste and digestibility of food so much that its beneficial nature is taken for granted; however, it induces profound changes in all types of foods. That these changes may be of concern to human health was established by research in the 1970s and 1980s ${ }^{9}$.

Various kind of mutagenic and carcinogenic HCAs are produced by heating foods. It has been postulated that thermal interaction of sugar and nitrogenic compounds results in dehydration, condensation, cyclisation and polymerization of the food surface contents and formation of $\mathrm{HCAs}^{10}$. All HCAs so far examined have demonstrated positive carcinogenicity in organs such as breast and colon, prostate, skin, lymphoid tissue, blood vessels, liver and hemopoietic system ${ }^{4,11,12}$.

The ingestion of roasted yam could therefore be construed as a form of exposure to HCAs which 
may be contained in the charred covers of roasted yams, suggesting that exposure of yam (a carbohydrate) to naked flame can also lead to the production of HCAs like the proteinacious foods. HCAs such as imidazoquinoline, imidazoquinoxaline, and phenylimidazopyridine cause cell proliferation with or without accompanying chronic cell damage ${ }^{8}$. Thus, the significant reduction in RBC count, $\mathrm{PCV}$ and $\mathrm{Hb}$ concentration could be attributed to the damaging effects of the HCAs; suggesting that the HCAs could be potent haemolytic agents. Osmotic fragility tests are used to establish the role of factors affecting the physical integrity of the erythrocytes ${ }^{13}$. Increased hemolysis could therefore be one of the ways by which HCAs cause reduction of RBC parameters, because of the increased osmotic fragility observed in the roasted yam group.

The present findings therefore suggest that the chronic ingestion of roasted yam could induce haemolysis. However, further studies aimed at elucidating the mechanism by which HCAs induce haemolysis will be worthwhile.

\section{REFERENCES}

1. Sugimura, T. (1995) History, present and future of heterocyclic amines, cooked food mitagens. In Adamson RH, Gusafsson JA, Ito N, Nagao M, Sugimura T, Wakabayashi $\mathrm{K}$, and Yamozoe Y, (eds). Heterocyclic amines: Possible Human Carcinogens. Princeton Scientific Publishing, Princeton NJ. pp. 214-231.

2. Sugimura, T. (1997) Overview of carcinogenic heterocyclic amines. Mutat. Res. 376:211-219.

3. Ito, N., Hasegawa, T., Sano, M., Tamano, S., Esumi, H., Takayana, S. and Sugimura, T. (1991) A new colon and mammary carcinogen in cooked food. 2- amino-1-methyl-6-phenylimidazole [4,5-b] pyridine (PhIp). Carcinogenesis 12:15031506.

4. Shirai, T., Sano, M., Takahashi, S., Hirose, M., Futakuchi, M., Hasegawa, R., Imiada, K., Matsomoto, K., Wakabayashi, K., Sugimura, T. and Ito, N. (1997) The prostate: a target for carcinogenicity of 2amino-1-methyl-6-phenylimidazole [4,5-b] pyridine (PhIp) derived from cooked foods. Cancer Res. 15:195-198.

5. Consultative Group on International Agricultural Research (1997) Priorities and Strategies for Resources Allocation during 1998-2000.

6. Rowett H.G.Q. (1974) The Rat As a Small Animal. Published by John Murray, London, 3rd Edition, pg 1

7. Olaleye, S.B., Iranloye, B.O., Salami, H.A. and Elegbe, R.A. (1999) Erythrocyte Osmotic Fragility and Other Blood Parameters in Rats Fed With Diets Containing Raw and Processed Soyabeans (Glycine max). Boiscience Research Communications, 11:107-112.

8. Sugimura T, (2000) Nutrition and dietary carcinogens. Carcinogenesis 21:387-395.

9. Felton JS, Malfatti MA, Knize MG, Salmon CP, Hopmans E.C. and Wu R.W. (1997) Health Risks of Heterocyclic Amines. Mutat Res; 376: 37-41.

10. Poerie, W.D., Wu, C.H. and Molund, V.P. (1986) Browning Reaction Systems as Sources of Mutagens and Antimutagens. Envir Hlth Perspect, 67:47.

11. Sugimura, T. (1986) Studies on environmental chemical carcinogenesis in Japan. Science 18:312-318.

12. Ohgaki H, Takayama, S. and Sugimura, T. (1991) Carcinogenicities of heterocyclic amines in cooked food. Mutat. Res. 259:399-410.

13. Parpart, A.K., Lorenz, P.B., Parpart, E.R., Gregg, J.R. and Chane, A.M. (1947) The Osmotic Resistance of Human Red Blood Cells. J Clin Invest 26:636. 